\title{
Law and Geology for the Anthropocene: Toward an Ethics of Encounter
}

\section{Alexander Damianos ${ }^{1}$ (D)}

Accepted: 11 January 2022

(c) The Author(s) 2022

\begin{abstract}
The Anthropocene has been observed as an opportunity to generate new legal imaginaries capable of revising incumbent assumptions of legal and political thought. What opportunities do such ambitions afford for communication between geological and legal thought? Responding to Birrell \& Matthews attempt to 're-story a law for, rather than of, the Anthropocene,' I wish to describe some ways in which the Anthropocene Working Group, who are pursuing formalisation of the Anthropocene as an official geological unit, are involved in a similar exercise of re-storying geology. The Anthropocene theme is brought to bear as a geological reality through material practices of measurement and correlation, as well as through the invocation of previous judgements of the evaluative committees associated with the formalisation of new geological unit. This effort amounts to a redefinition of the practices of geological observation, i.e. what counts as geologically relevant and why. In keeping with the theme of an 'ethics of encounter', as encouraged by Birrell and Matthews, this article suggests that the AWG's effort provides a model with which the elaboration of 'laws for the Anthropocene' might correspond.
\end{abstract}

Keywords Anthropocene - GSSP · Ethics of encounter · Rock · Fossil · Geology $\cdot$ Science and law

\section{Introduction}

In a recent issue of Law \& Critique, a series of articles argued for the elaboration of law for rather than of the Anthropocene thesis (Grear 2020; Birrell and Matthews

Alexander Damianos

a.n.damianos@cwts.leidenuniv.nl

1 Centre for Science and Technology Studies, University of Leiden, Kolffpad 1, 2333 BN Leiden, Netherlands 
2020a). The Anthropocene, in this context, is taken to refer to 'a new geological epoch brought about by the practices and excesses of consumption, production and habitation' (Birrell and Matthews 2020a, p. 233), wherein 'human agency manifest in consumption, production and habitation practices has fundamentally ruptured planetary history' (Birrell and Matthews 2020b, pp: 275-276). Law of the Anthropocene is taken to refer to 'law as coloniality and neo-coloniality-law complicit in ongoing forms of eco-violence, economic predation and the unparalleled imposition of precarity on humans and non-humans alike' (Grear 2020, p. 355). 'Law of the Anthropocene' is figured as a shorthand for the primacy of Eurocentric, masculinist, colonising legal imaginary, consolidated in the figure of the 'civilizing actor'; the sole benefactor of a narrative of rights (Grear 2020, p. 356). Discussion of obligations or duties, by contrast, is scarce in the discourse that characterises this law of the Anthropocene (Henkin 1990; Birrel and Matthews 2020a).

In pursuit of an articulation of 'law for the Anthropocene'-i.e. a legal imaginary that could critically respond to, rather than affirm a legal imaginary founded on colonial, masculinist, disembodied necropolitics (Grear 2020; Banerjee 2008; Yusoff 2018) - Birrell and Matthews insist on an acknowledgement of obligations as a way of articulating a legal imaginary of the Anthropocene. The authors identify this opportunity as an 'ethics of encounter': 'an attentiveness and responsivity to diverse accounts of authority, normativity, and legal subjectivity... in an effort to acknowledge the positioning of legal actors within a range of geological and ecological forces, rather than set against a routinely othered "Nature"" (Birrell and Matthews 2020b, p. 289). Unexpected encounters between law and the proposed Anthropocene epoch are hardly abstractions. When Nobel laureate Paul Crutzen first suggested the Anthropocene term, a start date or 'lower boundary' (a point in the material rock record where strata demonstrating the unique material characteristics associated with the proposed Anthropocene geological unit are agreed to have begun) of 1800 was tentatively recommended, coincident with James Watt's patenting of the steam engine (Crutzen and Stoermer 2000; Crutzen 2002; Pottage 2020).

This article is supportive of the above-mentioned efforts to widen the scope of the newly articulated terrain of 'law for the Anthropocene'. I am inspired by the contributions that special issue made concerning how legal imaginaries may be restoried in light of the Anthropocene hypothesis. However, my central argument is that perhaps geology is already one step ahead of critical legal theory in 're-storying' for the Anthropocene. Critical legal accounts of the Anthropocene theme that seek to widen the horizons of predominant legal imaginaries could be further realised by acknowledging the work of those geologists actively involved in the formalisation of an Anthropocene unit. Birrell and Matthews speak of the 'apparent disorientations of the Anthropocene [that] might allow for a generative reorientation of some of the central presuppositions of modern legal and political thought' (2020a, p. 276). Positioning the imagined legal actor, or observer, within ecological and geological forces, as they suggest, is one strategy of encouraging such generative reorientation. Reorienting legal and political thought, in other words, is realised through repositioning the legal actor. Their acknowledgement of post-colonial critiques of predominant legal imaginaries is a further aspect of that effort in repositioning. This paper, however, focuses on the possibilities that can be opened up for the project of reorienta- 
tion, or re-storying law for the Anthropocene, through closer engagement with the critical efforts of stratigraphers who are, likewise, actively crafting a narrative of the ecological and geological forces that are thought to make up the as yet informal 'Anthropocene unit'. That effort involves a repositioning of its own, to the extent that it positions humanity at the centre of ongoing geological events, as a geophysical force. It also renders human agency redundant, to the extent that human existence is counted as one among a long list of passing phenomena. In either case, the Anthropocene entails a reorientation of the themes of 'human' and 'environment', and consequently, a re-storying of the subject that is oriented within that environment.

Examining some of the ways that stratigraphers attempt to undertake the effort of reorientation that the Anthropocene implies, and the predicaments they face in doing so, might therefore be of interest to those who wish to re-story law for the Anthropocene. As I will recount, the process of defining a new unit, such as the Anthropocene, entails the eliciting of accounts from fossils, rocks, and sediment in intriguing ways. They acquire an agency of their own that geologists must actively collaborate with in the effort to satisfy both their colleagues and the idiosyncratic procedures according to which new units are formalised. Consequently, and continuing Birell and Matthews notion of an 'ethics of encounter', critical legal theory that seeks to address the implications of the Anthropocene theme for law, would do well to avoid blackboxing the Anthropocene as a defined premise, and encourage active engagement with the critical work of geologists as a strategy of re-storying (whether law or geosciences) for the Anthropocene. If elaborating law for the Anthropocene is, in part, an effort to position the legal actor, or observer, within ecological and geological forces, rather than against a routinely othered 'Nature,' then it is necessary for critical legal theory to think seriously with geologists who seek to elaborate geology, likewise, for the Anthropocene. In other words, entailed in the task of re-storying law for the Anthropocene is the necessity to take up and include the work of geologists as continuous with the work of critical legal theory. Otherwise, critical theory risks trading in one reductive trope ('a routinely othered "Nature"') for another (a routinely othered set of 'ecological and geological forces'). Re-storying law for the Anthropocene requires acknowledgement of practices quite foreign to law, such as geology, precisely because positioning the legal actor within geological forces is acknowledged as central to that task. In this article, I want to offer some preliminary suggestions of what such an acknowledgement might look like.

\section{'Re-storying' Geology for the Anthropocene}

How is geology being re-storied in light of, or for, the Anthropocene? Formalisation and definition of new geological units occurs through a rigid and hierarchical process of evaluation. Geologists are assigned to a Working Group, to examine the adequacy of a proposed new unit, understood within the discipline first and foremost as an amendment to the Geologic Time Scale, which is the constitutive document of the discipline of geology, governing the distribution of geologic time over the entirety of Earth's 4.5 billion years, as well as the rock record that has amassed therein (Gradstein et al. 2020). Since 2009, the Anthropocene Working Group (AWG) - a team 
of geologists, archaeologists, historians of science, and even a lawyer-have been engaged in an ongoing effort to formalise the Anthropocene as a unit of the Geologic Time Scale. ${ }^{1}$ The Scale is an organising device, a constitutive document that assembles, in one place, the current consensus concerning the distribution of geological time and space. More generally, it indicates what matters to practitioners, what that mattering means, and what can and cannot be argued (Latour 1986). Of course, the normative influence of a document such as the Geologic Time Scale also provides scope for controversy within the discipline of geology, i.e. it also frames debates and disagreements between geologists, as I shall explain shortly.

As in all disciplines, such controversy is constant and persistent. A mechanism has been devised in order to resolve what controversy precipitates from the Geologic Time Scale; and this mechanism frames the efforts of the AWG to formalise the Anthropocene as a geologic unit. Formalisation of the Anthropocene as a geological unit entails the submission of a proposal by the AWG to an evaluative hierarchy that oversees and manages the Geologic Time Scale. When the AWG eventually complete their proposal they will submit it to an organisation called the Subcommission on Quaternary Stratigraphy (SQS), a body of geologists that oversee and coordinate the classification of geological units within the last sixty-nine million years, i.e. since the Quaternary began. A panel of sixteen geologists, with expertise in the various rock sections that comprise the Quaternary, review the proposal and determine its validity by way of a popular vote. If a $60 \%$ majority is confirmed in favour of the proposal for a new unit within the Quaternary, the proposal is forwarded to the International Commission on Stratigraphy (ICS). The ICS manage the classification of the entirety of the geological record. They publish the International Chronostratigraphic Chart, where all geological units are listed, which is the basis for the Geologic Time Scale (Cohen et al. 2013; Gradstein et al. 2020). The ICS is comprised of three voting members who review the proposal for a new unit following its approval by the SQS, and likewise approve it with a $60 \%$ majority. After ICS approval, the proposal is forwarded to the International Union of Geological Sciences (IUGS). The IUGS is a professional body that seeks to represent the coordination and promotion of geological sciences globally (Finney 2014). They publish the journal Episodes, and organise the International Geological Conference, both of which are pre-eminent venues for dissemination of geological research. The IUGS, much like the ICS, is comprised of a panel of three voting members who review the proposal once approved by the SQS and ICS. If they approve with a $60 \%$ majority, the proposal is at last formally ratified, and a new unit is added to the Geologic Time Scale. Formal ratification is accompanied by an article in the journal Episodes explaining the novel characteristics of the rock associated with the new unit, and a description of the new unit's designated lower boundary section, known as the Global Boundary Stratotype Section and Point (GSSP-more on this soon).

The process of formalising a new geological unit therefore entails a series of highly idiosyncratic techniques of measurement, correlation, and historicization, according to which geologists solicit accounts from rocks and fossils across the world in their

\footnotetext{
${ }^{1}$ The complete list of AWG members is available at their website: http:/quaternary.stratigraphy.org/ working-groups/anthropocene/.
} 
efforts to establish an authoritative geohistorical narrative of the Earth. Observations are coded in a manner consistent with the precedent of previous amendments to the Geologic Time Scale (Zalasiewicz et al. 2017a; Zalasiewicz et al. 2019b), as well as the preferences of voting members as made apparent in their publications (Finney 2014; Finney and Edwards 2016; Gibbard and Walker 2014; Edgeworth et al. 2019). It is evident, furthermore, in the way new kinds of rock and fossil are brought to bear on the evaluative process, to elicit a favourable response from the hierarchical authorities that issue the final judgement on the organisation of the Geologic Time Scale, and to determine who and what is allowed to speak on behalf of historically and materially significant episodes of Earth history as they are acknowledged and ratified into the Scale.

\section{The International Chronostratigraphic Chart}

The Geologic Time Scale divides Earth's 4.5 billion years, and the rock that accumulated therein, into approximately one hundred and twenty units. These units occur with varying significance, arranged according to a hierarchical rank. For example, we currently reside in the Meghalayan Stage/Age, occurring within the Holocene Series/Epoch, within the Quaternary System/Period, in the Cenozoic Erathem/Era, in the Phanerozoic Eon/Eonothem. The rank occurs according to the significance of the event or boundary that defines it. The Phanerozoic, which is a unit of the largest scale of Erathem/Era, begins approximately five-hundred-and-forty-one million years ago with the appearance of an abundance of life forms (derived from the Greek phanero: 'apparent' and zoi: 'life'). The Meghalayan, which occurs at the smallest scale of Stage/Age, is defined by an aridity event approximately four thousand years ago that is evident in rock sections around the world (Head 2019). Confusingly, the Geologic Time Scale is based on the International Chronostratigraphic Chart, a further document published by the International Commission on Stratigraphy. However, the two documents convey the same information under two different names (Gradstein et al. 2020; Gibbard and Walker, 2014). ${ }^{2}$

The dual terminology applied to each unit refers to their simultaneous classification as temporal and material units. The Chart acknowledges the simultaneity of time and space in geological classification through the application of a 'dual hierarchy,' wherein each unit is designated simultaneously as a temporal and physical duration. Units of the Chart are classified as both geochronological (referring to events in earth history) and chronostratigraphic (the rock that accumulates within a geochronological, or temporal, period) entities. These two hierarchies are represented as synchronous on the Chart. In predominant geological classificatory strategies, depth refers to distance in time (Parikka 2014). As material, such as soil, rock, ice, dust, or palaeontological remains are deposited, geological sections grow upward, acquiring new layers according to semi-regular intervals. Geologists use these layers as a way to apply a chronological proxy to the depth at which sections are defined, counting

\footnotetext{
${ }^{2}$ For the Geologic Time Scale, see Gradstein et al. 2020. For the International Chronostratigraphic Chart, see Cohen et al. 2013.
} 
down from the top (or present day). The Holocene GSSP is defined at a rock section located $14292.45 \mathrm{~m}$ below the surface of the Greenland ice sheet (Walker et al. 2018). When geologists refer to the lower boundary of the Holocene, however, they tend to refer to a temporal definition (approximately 11,700 years ago) rather than the depth, because although the material associated with Holocene rock is thought to have been deposited at approximately the same time around the world (for example as a result of a mass extinction event that changes the fossil content of rock synchronously), Holocene rock does not begin at the same depth everywhere in the world. A temporal definition therefore provides a more stable referent for talking about stratotypes than depth. The Chart is therefore a medium with which temporal and spatial definitions are rendered interchangeable.

Standards such as the units of the Chart are materially mediated. The way in which geologists classify and discuss units is contingent on the material strategies according to which rock sections are measured and dated. What qualifies statements, observations, or measurements as geological is not an innate quality, but a practice of association. Through such practices, 'the geological' is qualified in two ways: firstly through reference to previous texts, arguments, and definitions that have appeared in the Chart as well as in the literature of peer-review journals; and secondly as a condition of the theme or issue that frame the AWG's formalisation process. The Global Boundary Stratotype Section and Point (GSSP) is a key example of the material dynamic of unit formalisation that the AWG are subject to in their formalisation effort.

\section{The GSSP}

The Geologic Time Scale provides the authoritative classification of geological time over the entirety of Earth's 4.5 billion years, as well as the rock that has amassed during that time. Such an exercise in classification is conducted using a set of material practices, devices, and techniques, whose employment helps verify the reliability of the definitions produced. The lower boundary of a geological unit, for example, has, since 1972, required the designation of a Global Boundary Stratotype Section and Point (known colloquially as a GSSP, or 'golden spike') (Gradstein et al. 2020). ${ }^{3}$ The GSSP is an agreed reference point within a rock section that demonstrates the material characteristics associated with the unit whose beginning (in both material and temporal terms) it defines. Most GSSPs are defined in rock sections where a significant palaeontological marker has occurred, i.e. a point in the rock record where a certain kind of fossil appears for the first time (Gibbard and Walker 2014; Gradstein et al. 2020). These material strategies constitute a set of mechanisms with which the inexhaustible variability of Earthly rock is interpreted, represented, and formatted in a manner that is consistent with the Chart. They also constitute the horizon of possibilities for the AWG's formalisation effort. A GSSP is a mandatory requirement of

\footnotetext{
${ }^{3}$ In 1972 the lower boundary of the Devonian was defined at a rock section in Klonk, Czech Republic. This was the first time that a GSSP had been used, supplanting the tradition of defining the lower boundaries of units in purely temporal terms (Gradstein et al. 2020).
} 
any proposal to formalise a new unit in the Chart. The application of techniques such as the GSSP is overseen by a hierarchical committee of geologists whose approval is required for an Anthropocene unit to be formalised (Gradstein et al. 2020; Zalasiewicz et al. 2019a).

Although the point designated by the GSSP exists in one place, it functions as a reference point for global correlation. The unique locality of the GSSP section is rendered universal through its correlation with other signals around the world, known as 'auxiliary sections.' Auxiliary sections are not simply the same rock as that which exists where the GSSP is defined. Rather, they are varying chemical, radiometric, or palaeontological signals that accommodate a narrative of what makes the unit whose lower boundary, or GSSP, they help to define, unique. For example, even though the AWG have yet to submit a formal proposal for an Anthropocene unit to the SQS, recently published literature indicates they are pursuing a GSSP definition at a site that demonstrates a clear chemical signal of a spike in plutonium isotopes, the product of fallout from nuclear weapons detonation beginning in the mid-twentieth century (Waters et al. 2015). The auxiliary sections, however, include a section in San Francisco Bay demonstrating a sharp increase in neobiota, or invasive species, beginning at the same time; an increase in plastics content of a section in the Black Sea; as well as a nuclear spike as recorded in a coral reef section in Australia (Zalasiewicz et al. 2017a). ${ }^{4}$

Yet historically, although the GSSP is thought to have introduced 'one single set of standard world-wide stages' (Hedberg 1968: 193), it is simultaneously acknowledged as an imperfect measure. Hollis Hedberg, who is often acknowledged as the architect of the GSSP (Cowie et al. 1986; Walsh 2005), acknowledges that 'palaeontological evidence of time in rock is always imperfect,' and that as far as accurate geological divisions are concerned, 'it is doubtful that their division points are marked by "natural breaks"' (Hedberg 1948, p. 447). Hedberg was of the opinion that the establishment of a universal, standardised code is of greater significance than total accuracy; the latter being an unrealistic abstraction in any case, given that the stratigraphic is always removed from the object of their investigation.

Hedberg's position is indicative of a more general ambivalence concerning the function and significance of the GSSP. The GSSP has often been referred to as a 'necessarily arbitrary marker' (Lucas 2018). By 'arbitrary' it is not meant that the designation of a GSSP is random, but rather that it is contingent on the discretion of the committees associated with the Chart, who issue judgements in favour or against proposals for new GSSP designations (Walsh 2004, pp: 145-147; Hedberg 1968; Remane 2003). The role of judgement is figured as a crucial strategy toward the reduction of complexity, thereby facilitating communication between geologists. A

\footnotetext{
${ }^{4}$ Other proposals have been suggested for the lower boundary, or GSSP of the Anthropocene. Lewis and Maslin $(2015 \mathrm{a} ; 2015 \mathrm{~b})$, for example, have made two separate proposals. However, the AWG have rejected both these proposals on grounds that they are not in keeping with the preferred methodology of the Geologic Time Scale (Zalasiewicz et al. 2015). This is an interesting scenario that I will not address in this paper for reasons of space, however it indicates the way in which the AWG invoke precedent of the Geologic Time Scale both as a strategy for increasing the scope of particular key categories, such as 'rock' and 'fossil', as well as a strategy of denouncing and excluding other proposals. See Lewis and Maslin 2015b, and Edgeworth et al. 2019.
} 
seminal textbook that continues to be used in most first year undergraduate courses in stratigraphy concludes a section on the GSSP, and the 'golden spike' - a colloquial term referring to the ritual of hammering a nail into the section where the GSSP is designated-with the following claim: 'it does not matter where the golden spike is hammered [...] so long as we can make an arbitrary decision, stop arguing about words and get on with the much more difficult (but much more rewarding) task of correlation' (Ager 1981, p. 79).

Elsewhere, attempts to define the function of the GSSP have varied significantly, indicating a fundamental tension concerning the definition of geological sections as both spatial and temporal entities. Former Chair of the ICS, Stephen Walsh, describes GSSP-defined units as 'classificatory pigeonholes' (Walsh et al. 2004, p. 205). In the official guidelines of the ICS, where the GSSP was first elaborated as a formal method of stratigraphic definition, the premise of global correlation of stratigraphic sections is concluded with an admission: 'in a world which is not ideal it is most unlikely that all selected Stratotype points can meet all the ideal requirements, and stratigraphy must be a practical subject and responsible to the needs of working geologists' (Cowie et al. 1986, p. 5).

The priority of organisations such as the International Commission on Stratigraphy would therefore appear to be the development of disciplinary standards that can facilitate communication and establish consensus. The GSSP is intended to emphasise the material definition of units, as not simply defined by the period in which a novel species of fossil, for example, begins to appear in sufficient abundance, but rather-with the advent of novel technologies that can provide more elaborate definitions of the rock record, such as magnetostratographic descriptions of rock on the basis of Milankovich cylces, or descriptions of the chemical constitution of rocksas entities that have distinct temporal and material definitions. The Holocene, for example, is both a period of time within the 4.5 billion years of Earth history, as well as a class of rock with distinct material properties. The purpose of the dual hierarchy is to allow geologists to distinguish between rock and time, i.e. to indicate whether they are talking about a property of rock or an event that occurred during a period of time. This is, admittedly, a very slight and subtle difference, yet it has generated significant controversy within the articles of geological journals. It is, furthermore, a distinction that the AWG must demonstrate a fluency in if they are to be successful in their effort to formalise the Anthropocene as a novel geological unit, and satisfy the preferences of the evaluative committees associated with the Chart who issue the final judgement.

Reception to the advent of the GSSP has been mixed. Opposition to the GSSP is divided. There are opponents who argue that the GSSP is not really any different to an abstracted, numerical date, because the simplification of a lower boundary to a single point that nevertheless is presented as globally consistent is inaccurate and unhelpful. By this account, the GSSP indicates that there is no longer any need for the dual hierarchy (Aubry 2007; Aubry 2009), since GSSP boundaries are material sections that are nevertheless typically referred to by the date they correspond to. Communication concerning geological units, it is argued accordingly, would be simplified by simplifying the dual hierarchy to a single set of terms (Zalasiewicz et al. 2004). Yet more than a standardised practice of measurement, the GSSP is a set of normative 
assertions that the contemporary stratigrapher is obliged to adhere to if their observations are to be received as properly geological: if their articles are to be included in peer-review journals of the discipline such as Episodes; or their proposals for new GSSPs to be incorporated into the Geologic Time Scale. That is to say, the GSSP is a material practice that informs how the geologist ought to record and present their observations. It consequently informs what can be brought to bear as the legitimate components of a geological observation: what is appropriately 'rock', what can count as a 'fossil', how to correlate strata globally and construct a narrative of geohistory accordingly.

I shall shortly describe some of the ways in which the AWG seek to adapt definitions of apparently fundamental categories, such as 'rock' and 'fossil' in an effort to bring the sets of concerns associated with the Anthropocene theme to bear on practices of classification such as the Geologic Time Scale. Yet one further point can be made to demonstrate the centrality of the evaluative committee associated with the Geologic Time Scale in shaping the way in which the AWG frame their formalisation effort. The GSSP is not the only way of defining a geological unit, but it is the one that is preferred by the committees of the ICS and IUGS who oversee the ratification of the International Chronostratigraphic Chart. As an example of how the evaluative process associated with the Chart frames the AWG's effort, one can look to the difference between an exclusively numerical definition (known as a Global Standard Stratigraphic Age, or GSSA) and the GSSP. Whereas the GSSP is thought to refer to a lower boundary Stratotype - that is, a section of rock that demonstrates the point in the material record where a rock with distinct chemical, palaeontological, or other geological characteristics begins - the GSSA refers to a numerical date that marks the beginning of a geological unit with an emphasis on its geochronological, or temporal, definition.

In their initial assessment of the Anthropocene as a geological unit, the AWG had considered a GSSA definition. This suggestion acknowledged Crutzen's initial articulation of the theme (Crutzen and Stoermer 2000; Crutzen 2002), wherein the Anthropocene was proposed to begin around the year 1800 coincident with the onset of the industrial revolution in Great Britain, together with the social and ethical commitments such a suggestion entailed, while adhering to the requirements of the Chart and the ICS:

In the case of the Anthropocene, however, it is not clear that-for current practical purposes - a GSSP is immediately necessary. At the level of resolution sought, and at this temporal distance, it may be that simply selecting a numerical age (say the beginning of 1800) may be an equally effective practical measure. This would allow (for the present and near future) simple and unambiguous correlation of the stratigraphical and historical records and give consistent utility and meaning to this as yet informal (but increasingly used) term. (Zalasiewicz et al. 2008, p. 7)

That proposal was met with a swift caution from the evaluative committee that oversees amendments to the Geologic Time Scale, emphasising that the GSSA was not an acceptable option for new units that have occurred within the Phanerozoic, especially 
for a unit as brief and recent as the Anthropocene would be. '[A] consensus is now developing in the ICS that abstract period definitions based on time can no longer be sustained... and that GSSAs must become GSSPs, using observable and correlative geological events' comment voting members of the ICS, '[ $t$ ]he designation of the base of the "Anthropocene" by a GSSA would therefore be at odds with the practice now being adopted in all others parts of the Geologic Time Scale' (Walker et al. 2015, p. 207).

The GSSP also provides a meta-reference of material with which to format a proposal as geologically relevant; as adhering to the requirements and preferences of the legislative hierarchy associated with the Chart. Many units were defined using GSSAs before GSSPs became a formal requirement of unit definition in the 1970's. Much stratigraphic research has therefore focused on the designation of GSSPs to existing units, rather than the definition of new units altogether (Gibbard and Walker 2014). New GSSP designations are typically accompanied by an article in the journal of the IUGS, Episodes. Those articles outline the reasoning behind the choice of the lower boundary Stratotype. The AWG therefore have at their disposal an archive of previous GSSP definitions that can be drawn on to provide a body of precedent according to which they can develop their own proposal for an Anthropocene unit. The AWG have drawn on the most recent units to be ratified into the Chart as a source of legitimacy for their proposal. In 2018, three new units were ratified: the Greenlandian, the NorthGrippian, and the Meghalayan, all of which are defined at the rank of Stage/Age as subunits of the Holocene Series/Epoch (Walker et al. 2018). The AWG have taken an interest in these new units because they bear some resemblance to the effort to define an Anthropocene GSSP. For example, their lower boundaries are all relatively recent in geological terms. The boundary of the oldest, that of the Greenlandian (which shares a lower boundary with the Holocene Series/Epoch), is 11,700 years old. The youngest of the new units, the Meghalayan, has a lower boundary that is dated at 4,200 years b2k. ${ }^{5}$ Furthermore, each of the lower boundary GSSPs for the three new units are defined in atypical rock bodies. The Greenlandian and NorthGrippian are both defined in ice cores. The Meghalyan GSSP is located in a speleothem from Mawluh Cave in India (Walker et al. 2018). Ice sheets and speleothems are categories of rock that would not have been widely considered as sites for GSSP candidates prior to the formalisation of the Greenlandian/Holocene lower boundary (Zalasiewicz et al. 2019a). That novelty provides the AWG with a blueprint according to which they may fold cement, coral reef, tree rings, and other recent material into the requirements of the GSSP (Waters et al. 2018).

The AWG have actively adapted their research trajectory in accordance with the preferences of the evaluative committees associated with the Chart. For example, the transition from a GSSA to a GSSP oriented proposal is attributed explicitly to feedback from the ICS. Citing an article written by the former chair of the ICS, one AWG paper notes that 'the geological community as a whole is more comfortable with a

\footnotetext{
5 The term 'b2k' is an abbreviation meaning 'before the year 2000'. Lower boundaries are often defined in reference to a fixed point in time because otherwise the date would have to change every few decades; whereas the purpose of referring to units by way of the date of their lower boundary is to facilitate ease of communication.
} 
GSSP,' and that 'therefore, the AWG is currently working towards candidate GSSP selection' (Zalasiewicz et al. 2017b, p. 53). The GSSP exercises a normative standard for the AWG's formalisation effort. It determines the practice of interpretation and representation of rock. In some ways, this is constraining, to the extent that the AWG are obliged to conduct their research in accordance with the preferences of the ICS. On the other hand, these constraints render the AWG's formalisation effort more attainable, as long as the AWG are prepared to acknowledge those preferences and format their proposal accordingly. In either case, observing the manner in which the AWG have attempted to accommodate the Anthropocene theme within the procedural and epistemic assumptions associated with the Geologic Time Scale is indicative of the way in which the Group's members are also involved in an exercise of re-storying geology for the Anthropocene. A further example concerning the refashioning of the categories of 'rock' and 'fossil' may serve as an illustration in this regard.

\section{Rocks and Fossils: Categories of Argumentation}

The Geologic Time Scale classifies the rock record, both temporally and materially. Yet the definition of 'rock' is dynamic. There are, after all, many kinds of rock (basalt, limestone, chalk, etc.). Recent developments in geological classification indicate that the category of rock is fundamentally open to change. This is a detail that the Anthropocene Working Group make significant use of in their effort to designate the Anthropocene within the rock record. In the articles that accompany the formalisation of the Meghalayan and Holocene, respectively, 'rock' is presented as a medium in/with which geochronological and chronostratigraphic events are recorded (Walker et al. 2008; Head 2019). 'As glacier ice is a sediment,' explain the authors of the Holocene GSSP proposal, 'defining the Holocene boundary Stratotype in an ice-core is as justified as basing a Stratotype on hard or soft rock sequences' (Walker et al. 2008, p. 7). It is also argued that the ice sheets from which the core was extracted accumulate in a similar pattern and frequency as traditional rock bodies. This means that just like other stratal bodies traditionally acknowledged as 'rock', ice cores laminate regularly, and record events in a manner that can be converted into numerical dates through the counting down of layers from the top, wherein each layer designates a discrete period of time (the duration each layer indicates varies by location; in the case of the NGRIP ice core, each layer recorded a year of sedimentary activity). Finally, the location of the NGRIP ice core is promoted as an argument in favour of the appropriateness of counting ice as rock. 'Because of its geographical location in the high latitude North Atlantic, Greenland is a sensitive barometer of hemispherical-scale climate change, and was especially so at the Pleistocene-Holocene transition' (Walker et al. 2008, p. 265). Coincidentally, this argument also served to convey climatic activity using the idiom of geological nomenclature.

'Rock,' in this sense, refers to a medium with which geological information is recorded and geologic units narrated, providing the grounds for its subsequent classification (Durham Peters 2003; Parikka 2015). 'Rock' is a discursive strategy according to which diverse phenomena are brought to bear on geological observation; and proposals for amendments to the Geologic Time Scale are evaluated, deliberated, 
and judged. The complete record of planetary change is inaccessible to the geologist. Geologists were not alive to witness the deposition of even the most recent official geological unit, the Meghalayan (which began approximately 4,200 years ago). Consequently, the major accomplishment of geological classification over the past fourhundred years since figures such as Nicolas Steno and Robert Hooke elaborated the forensic capacity of fossils, and since Giovanni Arduino, James Hutton and Charles Lyell elaborated a systematic theory of planetary change in the guise of 'uniformitarianism'-i.e. that observed changes in the present are indicative of changes that have been ongoing for millennia (what Durham Peters calls 'the confidence in the sameness of geological processes across historical time'(2003, p. 400)) - has been in finding a way to make material in the present account for changes in the 'deep past' of Earth's 4.5 billion year history (Gould 1987; Gibbard 2019; Rudwick 2014). A significant component of the category 'rock' are fossils. The prevalence of fossils in the history of geological classification distinguish geology as the original forensic science (Pottage 2018). Geologists have traditionally been reliant on fossils to provide them with accounts of their object: rock sections. Fossils entail a strategy of soliciting accounts from the 'non-living', furnishing a narrative of geological deep time (Yusoff 2018; Povinelli 2016).

The use of fossils in classifying, narrating, and refashioning both rock and geologic units can be briefly traced genealogically. When Nicolas Steno discovered artefacts on a Tuscan mountaintop in the Seventeenth Century that resembled the teeth of a shark, encased within rock, it revealed the possibility of a temporality far greater than the one indicated by the Bible (Rudwick 2014). Scripture provided an initial source of explanation: the teeth had been risen into a 'great diluvial soup' by the Great Flood, recounted in the Book of Genesis, and then redeposited in unusual places (Gould 1987). Yet the tooth's encasement in rock indicated that it must be far older than any of the deposits within which the teeth-like objects were found. At around the same time, in England, Robert Hooke delivered a presentation concerning a series of unusual artefacts he had come across in preparation of his book 'Micrografia', an early exposition of the microscope (Hooke 1665). The microscope allowed Hooke to observe how charcoal and rock specimens were processed materials, yet evidently organic. The question therefore remained of what history those artefacts possessed, revealing a chronology that was particular to 'natural' artefacts. In other words, human civilisation was not exclusive in possessing a history:

There is no coin can so well inform an Antiquary that there has been such or such a place subject to such a Prince, as these [fossil shells] will certify a Natural Antiquary, that such and such places have been under the Water, that there have been such kind of Animals and, there have been such and such preceding Alterations and Changes of the superficial Parts of the Earth: And methinks Providence does seem to have design'd these permanent shapes, as Monuments and Records to instruct succeeding Ages of what past in preceding [ages]. And these [are] written in more legible Characters than Hieroglyphics of the ancient 
Egyptians, and on more lasting Monuments than those of their vast Pyramids and Obelisks. ${ }^{6}$

The premise that a new category of artefact, 'natural antiquities', could recount a history of the planet as distinct from human history, was a subtle yet radical gesture. While the Bible had traditionally been perceived as the authoritative source on historical circumstance, these new artefacts revealed a history that was just as old as the events recounted in the Bible, if not older. A forensic strategy was therefore inaugurated, wherein the events of the Bible could be compared with the record indicated by natural antiquities. Whereas it had been traditional to use the Bible to recount the sequence of events on earth, 'natural antiquities' could be mobilised to recount and 'externally' validate scriptural chronology.

With the GSSP and the Stratotype section, fossils become folded into a disciplinary framework for classifying rock units and standardising geological observation. Fossils are both a medium with which to narrate geological observations, as well as a way to format them in accordance with the proceduralism entailed in the formalisation of new units of the Geologic Time Scale. Geologists piece together an account of the gradual changes that Earth has endured over billions of years by soliciting accounts from its material remains. The GSSP and the Chart, however, ensure that any such narratives are approved by a central evaluative body that judges the reliability of those accounts in the final instance. As a consequence, the AWG have to employ the category of 'fossil' in a manner that satisfies the normative assumptions and preferences of that body. The work of the AWG entails the active construction of the Anthropocene unit as a discursive artefact that accords with the preferences of the ICS and IUGS voting members.

Members of the AWG have proposed the term 'technofossil' to emphasise the novelty of post-WWII sediments (Zalasiewicz 2014). In an effort to demonstrate the substantial material record that has accumulated since the proposed mid-twentieth century beginning, argued by some to be too brief for there to be any geologically significant record, the AWG pursue the figure of the 'technofossil', a composite of the 'technosphere' (Haff 2014; Zalasiewicz et al. 2017c). Technofossils, as the idea is advanced by AWG members, are the material remains of socio-technical activity, ranging from the cement foundations of office buildings to plastics laid down in stratigraphic deposits, to the accumulation of chicken bones as a result of global industrialised agriculture (Zalasiewicz et al. 2014; Bennett et al. 2018). The technosphere hypothesis amounts to a strategy by which the AWG seek to expand the category of rock and fossil in a manner that is in keeping with the established significance of palaeontology for chronostratigraphic definition, such as in the requirement of a lower boundary 'stratotype' or GSSP, often defined by the first appearance of a novel kind of fossil. Arguments such as the technofossil are a demonstration of the AWG's effort to render arguments for a formal Anthropocene unit favourable to the ICS and IUGS voting members, which would otherwise be met by them with disapproval, or even indifference as simply not relevant to geology. In doing so, the category of 'fos-

\footnotetext{
${ }^{6}$ This episode is recounted in Rudwick (2014, pp: 9-30). See also Rappaport (1986).
} 
sil' is extended, bringing geological practices of classification into contact with the socio-technical anxieties incorporated in the wider Anthropocene theme.

Specifically, the 'technofossil' allows the AWG to speak of a very recent temporality as geological, through the familiar and procedurally acceptable idiom of the fossil. Even though the AWG currently pursue a definition of the Anthropocene beginning in the mid-twentieth century, the fossil therefore remains a central medium with which the AWG develop their proposal for an Anthropocene unit (Zalasiewicz et al. 2019a). The technofossil extrapolates from the categorical logic of the fossil in service of the AWG's formalisation effort. As Pottage has indicated, the technofossil reverses the geological forensic approach: 'instead of beginning with the fossil and eliciting context from it, one begins with context and finds the Leitfossil for that context' (Pottage 2019, p. 154). The AWG justify this reversal by reference to Crutzen's original contribution: 'one may take the environmental trends picked out as of major significance to contemporary global change by the Earth system science community [of which Crutzen, as former Chair of the International Geo-Biosphere Program, was a part] and consider whether or not they will leave a recognizable signal within strata that may then be used as a basis for chronostratigraphical units' (Zalasiewicz et al. 2016 p. 87).

The technofossil, in other words, fashions a geological temporality that accommodates the comparatively brief duration of a potential Anthropocene unit within the expansive 4.5 billion year history represented in the Geologic Time Scale. It facilitates the articulation of an Anthropocene lower-boundary consistent with the requirements of the GSSP, using materials that have not previously been acknowledged in that context, such as nuclear fallout, and various novel material subsumed under the banner of the technofossil (Zalasiewicz et al. 2017b). Whereas it has been argued (Autin and Holbrook 2012; Gibbard and Walker 2014; Finney 2014; Finney and Edwards 2016) that events associated with the Anthropocene unit are simply too recent to justify a new unit of the Chart (many geological boundaries have margins of error far greater than the total elapsed time of an Anthropocene unit), the premise of the technofossil would suggest that there is nevertheless sufficient material in appropriate abundance and adequately distributed around the world to support the stratigraphic expression of a mid-twentieth century event, and the subsequent definition of an Anthropocene unit. The AWG, after all, only seek to define the lower boundary, or 'beginning' of an Anthropocene unit as per the GSSP requirements (Head 2019). It may eventually last as long as any other formal geological unit.

\section{Law and Geology for the Anthropocene}

I have provided a description of some of the strategies engaged by the AWG in their effort to formalise the Anthropocene as a geological unit. The purpose of these efforts is to elaborate a narrative of the Anthropcoene theme that is consistent with the requirements for formalisation of novel geological units in the Geologic Time Scale. Creatively refashioning categories such as the fossil, along with 'rock', 'sediment', and even the temporality of geological history, the AWG's effort to formalise an Anthropocene unit is simultaneously an effort to re-situate the observer within 4.5 
billion years of geo-history. Although the figure of the human remains ambiguous and problematic in the AWG's literature (Yusoff 2018; Grear 2015; Haraway 2016), the prospect of a formal Anthropocene unit has significant implications for the stories that are told about what the human is and how the human is figured in relation to an environment; that is, ecologically. The Anthropocene narrative therefore also has consequences for the way that geological and ecological forces are thought of. They work against the premise of Nature as a routinely othered backdrop, and instead acknowledge, to quote one example, 'the Earth's biosphere,' as profoundly impacted by 'changing patterns of human resource use and food consumption' (Bennett et al. 2018, p. 1).

The AWG's formalisation effort therefore inevitably bears on Birrel and Matthew's interest in reorienting the central presuppositions of legal imaginaries. This is especially the case given that Birrell and Matthews identify as central to the task of re-storying law the positioning of law's imagined 'legal actor' within ecological and geological forces, rather than against a routinely othered 'Nature.' The advent of the Anthropocene is mobilised by Birrell and Matthews as an occasion for such 'restorying,' yet does so at times implying that the Anthropocene is a settled term within geological nomenclature. In response to their compelling argument, I simply wish to point out that the Anthropocene is nowhere near settled within geological circles, and that an appreciation of why that is the case, and how various stakeholders within geology attempt to resolve dispute about what the Anthropocene means for geological knowledge production, might facilitate the articulation of novel legal imaginaries beyond the familiar repertoire of law of the Anthropocene. Perhaps, in other words, the articulation of law for the Anthropocene (moving away from the constrained paradigm of laws of the Anthropocene; or legal imaginaries that are symptomatic, rather than responsive to, the predicament the Anthropocene theme is thought to entail), might be enriched by an appreciation of the project of re-storying that is, in fact, common to both critical legal theory as well as geology in light of the unusual efforts of the AWG. To position law within ecological and geological forces implies bringing geological observations into the work of critical legal theory, as a strategy of overcoming the reductive and extractivist narrative of rights that characterises law of the Anthropocene.

Might the efforts of the AWG to re-story geo-history as represented in the Geologic Time Scale, through media such as the fossil, rock, and the GSSP, demonstrate the construction of those ecological and geological forces within which Birrell and Matthews seek to situate the legal actor of a law for the Anthropocene? Might strategies such as the technofossil indicate some of the ways in which legal subjectivity for the Anthropocene is elaborated? The theme of the 'technofossil' indicates that the AWG's effort is as much about the fabrication of the category of 'fossil' as it is about the articulation of a novel understanding of planetary history, and the agency of human activity as an extension thereof. The AWG's formalisation effort is an exercise in bringing past applications of classificatory devices to bear on their formalisation effort in the present. It is not so much the Anthropocene that is being constructed as a geological unit; rather, the parameters of geological observation are engaged, extended, and applied in novel and controversial ways. This is not unique to a potential Anthropocene unit; as mentioned previously, in designating GSSPs in ice sheets 
and speleothems, the sub-units of the Holocene have also refashioned categories of geological classification in the moment of their application. Yet the AWG, which counts among its members a variety of disciplinary expertise far greater than any geological Working Group before, appears to be especially committed to practices of re-storying the methods and assumptions of the discipline of geology as a way of bringing chronostratigraphy into dialogue with a set of concerns that have so far not registered in geohistorical accounts.

The AWG's formalisation effort, and the narrative it entails, is often problematic. Yet if the articulation of laws for the Anthropocene entails an ethics of encounter, wherein the assumed subject of law is rethought in accordance with the perceived implications of the Anthropocene theme, then perhaps taking that encounter seriously requires that we think seriously with the work of geologists. If an 'ethic of encounter' entails an acknowledgement of the situatedness of legal observation within the processual dynamics of ecological and geological forces, then perhaps that project begins with a comprehensive engagement with the critical practices of re-storying that the AWG are already involved in. Otherwise critical legal theory runs the risk of trading in one reduction "the routinely othered "Nature"' for another: "ecological and geological forces.' Yet it would appear that the articulation of law for the Anthropocene entails an active engagement with the strategies according to which the location of the legal actor is (perpetually) (re)constructed. Toward the articulation of laws for the Anthropocene, active engagement with geoscientists and geoscientific literature seeking to challenge narratives of earth history, along with the categories with which such narratives are composed, can be engaged as a strategy of critical reflection on the presuppositions underlying modern legal and political thought.

This article has attempted to demonstrate what some of those common strategies or themes of argumentation are, as a way to suggest some avenues for acknowledging that research of any kind that is for rather than of the Anthropocene must acknowledge the discursive spaces it cohabits with other, unfamiliar discursive strategies. In order for legal theory to develop the kinds of encounters that might characterise law for rather than of the Anthropocene, it is necessary to develop theoretical practices that extend beyond legal theory's self-understandings (predicated on the consistency of doctrines, legal principles, etc.), incorporating insights from the 'ecological and geological forces' within which a law for the Anthropocene situates legal actors. The work of geologists such as those involved in the effort to formalise an Anthropocene unit provide one source of such insights. The task is not simply to replace a vocabulary of 'Nature' with 'ecological and geological forces', but to actively integrate the ways in which those forces are being debated and actively constructed from within the geosciences into the extended task of a legal theory appropriate for the articulation of law for the Anthropocene.

Acknowledgements I would like to thank Stewart Motha, Bernard Keenan, Sarah Keenan, Maria Drakopoulou and Sarah de Rijcke for their thoughts and comments during the drafting of this article. I am exceptionally grateful to two anonymous reviewers for their constructive and generous feedback.

Open Access This article is licensed under a Creative Commons Attribution 4.0 International License, which permits use, sharing, adaptation, distribution and reproduction in any medium or format, as long as you give appropriate credit to the original author(s) and the source, provide a link to the Creative 
Commons licence, and indicate if changes were made. The images or other third party material in this article are included in the article's Creative Commons licence, unless indicated otherwise in a credit line to the material. If material is not included in the article's Creative Commons licence and your intended use is not permitted by statutory regulation or exceeds the permitted use, you will need to obtain permission directly from the copyright holder. To view a copy of this licence, visit http://creativecommons.org/ licenses/by/4.0/.

\section{References}

Ager, Derek. 1981. The Nature of the Stratigraphic Record. London: Wiley.

Aubry, Marie Pierre. 2007. Chronostratigraphy beyond the GSSP. Stratigraphy 4 (2/3): 127-134.

Aubry, Marie Pierre. 2009. Thinking of deep time. Stratigraphy 6 (2): 93-99.

Autin, Whitney, and John Holbrook. 2012. Is the Anthropocene an issue of stratigraphy or pop culture? GSA Today 22 (7): 60-61.

Banerjee, Subhabrata Bobby. 2008. Necrocapitalism. Organization Studies 29 (12): 1541-1563.

Bennett, Carys E., Richard Thomas, Mark Williams, Jan Zalasiewicz, Matt Edgeworth, Holly Miller, Ben Coles, Alison Foster, and Emily J. Burton and Upenyu Marume. 2018. The broiler chicken as a signal of a human reconfigured biosphere. Royal Society Open Society 5 (12): https://doi.org/10.1098/ rsos. 180325 .

Birrell, Kathleen, and Dan Matthews. 2020a. Laws for the Anthropocene: Orientations, Encounters, Imaginaries. Law \& Critique 31: 233-238.

Birrell, Kathleen, and Dan Matthews. 2020b. Re-storying Laws for the Anthropocene: Rights, Obligations and an Ethics of Encounter. Law \& Critique 31: 275-292.

Cohen, Kim, Stan Finney, and Phil Gibbard, et al. 2013 (updated). The ICS International Chronostratigraphic Chart. Episodes 36: 199-204.

Cowie, John, Willi Ziegler, and Arthur Boucot, et al. 1986. Guidelines and Statutes of the International Commission on Stratigraphy. Frankfurt: Commission on Stratigraphy of the International Union of Geological Sciences.

Crutzen, Paul and Eugene Stoermer. 2000. The “Anthropocene.”. IGBP Global Change Newsletter 41: 17-18.

Crutzen, Paul. 2002. The Geology of Mankind. Nature 415 (23): https://doi.org/10.1038/415023a.

Crutzen, Paul. 2006. Albedo Enhancement by Stratospheric Sulfur Injections: A Contribution to Resolve a Policy Dilemma? Climatic Change 77: 211-219.

Crutzen, Paul, and Christian Schwägerl. 2011. Living in the Anthropocene: Toward a New Global Ethos. Yale Environment 360. https://e360.yale.edu/features/ living_in_the_anthropocene_toward_a_new_global_ethos.

Crutzen, Paul, and Eugene Stoermer. 2000. The "Anthropocene". The IGBP Global Change Newsletter 41: 17-18.

Durham Peters, John. 2003. Space, Time, and Communication Theory. Canadian Journal of Communication 28: 397-411.

Edgeworth, Matt, Erle Ellis, and Phil Gibbard, et al. 2019. The chronostratigraphic method is unsuitable for determining the start of the Anthropocene. Progress in Physical Geography 43 (7): https://doi.org /10.1177/2F0309133319831673.

Finney, Stan. 2014. The 'Anthropocene' as a ratified unit in the ICS International Chronostratigraphic Chart: fundamental issues that must be addressed by the Task Group. In Waters, C., Zalasiewicz, J., Williams, M., et al. A Stratigraphical Basis for the Anthropocene. London: Geological Society of London Special Publication 395: 23-28.

Finney, Stan, and Lucy Edwards. 2016. The "Anthropocene” epoch: Scientific decision or political statement? GSA Today 26 (3): 4-10.

Gibbard, Phil, and Mike Walker. 2014. The term 'Anthropocene' in the context of formal geological classification. In Waters, C., Zalasiewicz, J., Williams, M., et al. A Stratigraphical Basis for the Anthropocene. London: Geological Society of London Special Publication 395: 29-38.

Gibbard, Phil. 2019. Giovanni Arduino - the man who invented the Quaternary. Quaternary International 500: 11-19. 
Gould, Stephen Jay. 1987. Time's Arrow, Time's Cycle: Myth and Metaphor in the Discovery of Geological Time. Cambridge: Harvard University Press.

Gradstein, Felix, James Ogg, and Mark Schmitz, et al. 2020. Geologic Time Scale.. Oxford: Elsevier.

Grear, Anna. 2015. Deconstructing Anthropos: A Critical Legal Reflection on 'Anthropocentric' Law and Anthropocene 'Humanity'. Law \& Critique 26: 225-249.

Grear, Anna. 2020. Legal Imaginaries and the Anthropocene: 'Of' and 'For'. Law \& Critique 31: 351-366.

Haff, Peter. 2014. Humans and technology in the Anthropocene: Six rules. The Anthropocene Review 1 (2): $126-136$

Haraway, Donna. 2016. Staying With the Trouble: Making Kin in the Chthulucene. Durham: Duke University Press.

Head, Martin. 2019. Formal subdivision of the Quaternary System/Period. Present status and future directions. Quaternary International 500: 32-51.

Hedberg, Hollis. 1948. Time-stratigraphic classification of sedimentary rocks. Bulletin of the Geological Society of America 59: 447-462.

Hedberg, Hollis. 1968. Some views on chronostratigraphic classification. Geological Magazine 105: 192-199.

Henkin, Louis. 1990. The Age of Rights. New York: Columbia University Press.

Hooke, Robert. 1665. Micrographia: or, Some physiological descriptions of minute bodies made by magnifying glasses: with observations and inquiries thereupon. Available at: http://ttp.royalsociety.org/ ttp/ttp.html?id=a9c4863d-db77-42d1-b294-fe66c85958b3\&type=book.

Latour, Bruno. 1986. Visualisation and Cognition: Thinking with Eyes and Hands. In H. Kuklick ed Knowledge and Society Studies in the Sociology of Culture Past and Present. London: Jai Press 6: 1-40.

Lewis, Simon, and Mark Maslin. 2015a. Defining the Anthropocene. Nature 519: 171-180.

Lewis, Simon, and Mark Maslin. 2015b. A transparent framework for defining an Anthropocene Epoch. The Anthropocene Review 2(2): https://doi.org/10.1177/2F2053019615588792.

Lucas, Spencer. 2018. The GSSP Method of Chronostratigraphy: A Critical Review. Frontiers in Earth Science 6 (191): https://doi.org/10.3389/feart.2018.00191.

Parikka, Jurri. 2014. The Anthrobscene. Minneapolis: University of Minnesota Press.

Parikka, Jurri. 2015. A Geology of Media. Minneapolis: University of Minnesota Press.

Peters, John Durham. 2003. Space, Time, and Communication Theory. Canadian Journal of Communication 28(4): https://doi.org/10.22230/cjc.2003v28n4a1389.

Pottage, Alain. 2012. The Materiality of What? Journal of Law and Society 39 (1): 167-183.

Pottage, Alain. 2018. Our Geological Contemporary. In Searching for Contemporary Legal Thought, eds. J. Desautels-Sein, and C. Tomlins, 177-196. Cambridge: Cambridge University Press.

Pottage, Alain. 2019. Holocene jurisprudence. Journal of Human Rights and the Environment 10 (2): 153-175.

Pottage, Alain. 2020. An Apocalyptic Patent. Law \& Critique 31: 239-252.

Povinelli, Elizabeth. 2016. Geontologies: A Requiem to Late Liberalism. Durham: Duke University Press.

Rappaport, Roy. 1986. Hooke on Earthquakes: Lectures, Strategy and Audience. The British Journal for the History of Science 19(2): 129-146.

Remane, Jurgen, Michael G. Bassett, and John Cowie, et al. 1996. Revised Guidelines for the Establishment of Global Chronostratigraphic Standards by the International Commission on Stratigraphy. Episodes 19 (3): 77-81.

Remane, Jurgen. 2003. Chronostratigraphic correlations: their importance for the definition of geochronologic units. Palaeogeography, Palaeoclimatology, Palaeoecology 196: 7-18.

Rudwick, Martin. 2014. Earth's Deep History: How It Was Discovered and Why It Matters. Chicago: University of Chicago Press.

Steffen, Will, and Wendy Broadgate, Lisa Deutsch, et al. 2015. The trajectory of the Anthropocene: The Great Acceleration. The Anthropocene Review 2(1): https://doi.org/10.1177/2F2053019614564785.

Walker, Mike, Sigfus Johnsen, and Olander Rasmussen, et al. 2008. Formal definition and dating of the GSSP (Global Stratotype Section and Point) for the base of the Holocene using the Greenland NGRIP ice core, and selected auxiliary records. Journal of Quaternary Science 24 (1): 3-17.

Walker, Mike, Phil Gibbard, and John Lowe. 2015. Comment on "When did the Anthropocene begin? A mid-twentieth century boundary level is stratigraphically optimal. Quaternary International 383: 204-207.

Walker, Mike, Martin Head, and Michael Berkelhammer, et al. 2018. Formal ratification of the subdivision of the Holocene Series/Epoch (Quaternary System/Period): two new Global Boundary Stratotype Section and Points (GSSPs) and three new stages/subseries. Episodes 41 (4): 213-223. 
Walsh, Stephen, and Felix Gradstein, and Jim Ogg. 2004. History, philosophy, and application of the Global Stratotype Section and Point (GSSP). Lethaia 37: 201-218.

Walsh, Stephen L. 2005. The role of stratotypes in stratigraphy. Earth-Science Reviews 69(3-4): 307-332. https://doi.org/10.1016/j.earscirev.2004.11.002

Waters, Colin, Jan Zalasiewicz, and Mark Williams, et al. 2014. A stratigraphical basis for the Anthropocene? In A Stratigraphical Basis for the Anthropocene, eds. C. Waters, J. Zalasiewicz, and M. Williams, et al, London: Geological Society. of London Special Publications 395.

Waters, Colin, James Syvitski, and Agnes Galuszka, et al. 2015. Can nuclear weapons fallout mark the beginning of the Anthropocene? Bulletin of the Atomic Scientists 71(3): https://doi.org/10.1177 /2F0096340215581357.

Waters, Colin, Jan Zalasiewicz, and Colin Summerhayes, et al. 2018. Global Boundary Stratotype Section and Point (GSSP): Where and how to look for potential candidates. Earth-Science Reviews 178: $379-429$.

Yusoff, Kathryn. 2018. A Billion Black Anthropocenes or None. Minneapolis: University of Minnesota Press.

Zalasiewicz, Jan, Alan Smith, and Patrick Brenchley, et al. 2004. Simplifying the stratigraphy of time. Geology 32 (1): 1-4.

Zalasiewicz, Jan, Mark Williams, and Alan Smith, et al. 2008. Are we now living in the Anthropocene? Geology Today 18 (2): 4-8.

Zalasiewicz, Jan, and Mark Williams, Colin Waters, et al. 2014. The technofossil record of humans. The Anthropocene Review 1 (1): https://doi.org/10.1177/2F2053019613514953.

Zalasiewicz, Jan, Colin Waters, and Anthony D. Barnosky, et al. 2015. Colonization of the Americas, 'Little Ice Age' climate, and bomb-produced carbon: their role in defining the Anthropocene. The Anthropocene Review 2 (2): https://doi.org/10.1177/2F2053019615587056.

Zalasiewicz, Jan, Will Stefen, and Reinhold Leinfelder, et al. 2016. Petrifying earth process: the stratigraphic imprint of key earth parameters in the Anthropocene. Theory, Culture \& Society 34 (2-3): $83-104$.

Zalasiewicz, Jan, Colin Waters, and Colin Summerhayes, et al. 2017a. The Working Group on the 'Anthropocene': Summary of evidence and recommendations. Anthropocene 19: 55-60.

Zalasiewicz, Jan, and Colin Waters, Alexander Wolfe, et al. 2017b. Making the case for a formal Anthropocene Epoch: An analysis of ongoing critiques. Newsletters on Startigraphy 50 (2): 205-226.

Zalasiewicz, Jan, and Mark Williams, Colin Waters, et al. 2017c. Scale and diversity of the physical technosphere: A geological perspective. The Anthropocene Review 4 (1): https://doi.org/10.1177 /2F2053019616677743.

Zalasiewicz, Jan, Colin Waters, and Mark Williams, et al. 2019a. The Anthropocene as a Geological Time Unit: A Guide to the Scientific Evidence and Current Debate. Cambridge: Cambridge University Press.

Zalasiewicz, J., Colin Waters, and Martin Head, et al. 2019b. A formal Anthropocene is compatible with but distinct from its diachronous anthropogenic counterparts: a response to W.F. Ruddiman's 'three flaws in defining a formal Anthropocene'. Progress in Physical Geography: Earth and Environment 43 (3): https://doi.org/10.1177/2F0309133319832607.

Publisher's Note Springer Nature remains neutral with regard to jurisdictional claims in published maps and institutional affiliations. 